\title{
What is the Impact of the Proportion of Solid Necrotic Content on the Number of Necrosectomies during EUS-Guided Drainage using Lumen-Apposing Metallic Stents of Pancreatic Walled-off Necrosis?
}

\author{
Andrada Seicean ${ }^{1,2}$, Cristina Pojoga ${ }^{2,3}$, Ofelia Moșteanu ${ }^{1,2}$, Sorana D. Bolboacă ${ }^{1,4}$, Mădălina Ilie ${ }^{5,6}$, Mihai Rimbaș, \\ Marcel Gheorghiu', Laura Lucaciu ${ }^{1}$, Adrian Bartoș ${ }^{1,2}$, Nadim Al Hajjar ${ }^{1,2}$, Vasile Șandru ${ }^{5,6}$, Gabriel Constantinescu, \\ Radu Seicean $^{1,8}$
}

1) Iuliu Hațieganu University

of Medicine and Pharmacy

Cluj-Napoca;

2) Regional Institute of

Gastroenterology and

Hepatology, Cluj-Napoca;

3) Clinical Psychology and

Psychotherapy Department

Babes-Bolyai University Cluj-

Napoca,

4) Department of Medical

Informatics and Biostatistics;

5) Carol Davila University

of Medicine and Pharmacy,

Bucharest;

6) Floreasca Emergency

Hospital, Bucharest;

7) Colentina Clinical Hospital,

Bucharest;

8) First Surgical Clinic,

Cluj-Napoca, Romania

\author{
Address for correspondence: \\ Andrada Seicean, M.D., Ph.D. \\ Regional Institute of \\ Gastroenterology and \\ Hepatology, Cluj-Napoca, \\ Romania \\ 19-23 Croitorilor street, \\ 400192, Cluj-Napoca, \\ Romania \\ andradaseicean@gmail.com
}

Received: 27.07.2020

Accepted: 19.10.2020

\section{ABSTRACT}

Background \& Aims: The fully-covered, lumen apposing metal stents are designed for one step placement, facilitating the direct endoscopic necrosectomy into the walled-off pancreatic necrosis. However, the prediction of the number of necrosectomy sessions in these patients is not known. This study evaluated the association between the proportion of solid necrotic material inside walled-off necrosis, as assessed during the endosonography placement of a lumen apposing metal stent, and the number of necrosectomies subsequently required.

Methods: Patients from three tertiary medical centers with symptomatic walled off pancreatic necrosis (pain, infection, gastric/biliary obstruction) at more than 4 weeks after onset of acute pancreatitis were retrospectively analysed. Proportion of solid necrotic debris was estimated during endosonography procedure of lumen apposing metal stents placement. Necrosectomy was performed when obstruction or inflammation occurred subsequently. Lumen apposing metal stents were removed after clearance of necrotic content.

Results: In 46 patients with successful lumen apposing metal stents placement, necrosectomy was performed in 39 patients $(72.78 \%)$. Performance of 3 or more necrosectomies was significantly associated with more than $50 \%$ pancreatic necrosis ( $\mathrm{p}=0.032$ ), but not with walled-off pancreatic necrosis size or location. Necrotic infection during lumen apposing metal stents stenting was associated with hypoalbuminemia, but not with necrosectomy requirement. Clinical success after a median follow-up of 13.37 months was $87 \%$.

Conclusions: Walled-off pancreatic necrosis with more than $50 \%$ solid necrotic content were associated with more necrosectomy procedures, requiering longer endoscopy time, intravenous sedations, and higher costs.

Key words: endosonography - drainage - pancreatic necrosis - metallic stent - acute pancreatitis.

Abbreviations: DEN: direct endoscopic necrosectomy; EUS: endoscopic ultrasound; IQR: interquartile range; LAMS: lumen-apposing metal stent; MRI: magnetic resonance imaging; MSOF; multisystem organ failure;WON: walled-off pancreatic necrosis.

\section{INTRODUCTION}

Necrotizing pancreatitis represents roughly $20 \%$ of acute pancreatitis cases, with a mortality up to $15 \%[1,2]$. About $50 \%$ of acute necrotic collections develop into walled-off pancreatic necrosis (WON), while among WONs only $20 \%-63 \%$ require further intervention [3-5]. Crosssectional imaging should be performed after four weeks from onset, for management planning [6]. Indications for drainage are infected necrosis or symptoms: abdominal pain, vomiting, jaundice, recurrent acute pancreatitis, fistulas; or persistent systemic inflammatory response [7].

Differentiating WONs from pseudocysts is important for management, as residual necrotic debris after insufficient drainage may cause secondary infection [8], but how the amount of solid necrosis affects the patient course has been infrequently studied.

Drainage followed by necrosectomy can be surgical, endoscopic through metallic stents, or percutaneous [9]. Endoscopic ultrasound (EUS) is preferred over other techniques because it avoids creating a pancreaticocutaneous fistula [3]. Endoscopic ultrasound drainage using lumenapposing metal stents (LAMSs) facilitates the insertion of an endoscope into the $\mathrm{WON}$, allowing direct endoscopic necrosectomy (DEN). Lumen-apposing metal stents showed 
better clinical success than plastic stents [odds ratio (OR) 3.37], with similar side effects [10]. However, the factors affecting the required number of DEN procedures, their optimal timing (at index EUS procedure/as needed), and the interval between sessions remain unclear. The present study evaluated the association between the proportion of solid necrotic material inside WON, as assessed during EUS placement of LAMS, and the number of necrosectomies subsequently required and outcomes of EUS drainage of WONs using LAMSs.

\section{METHODS}

The research complied with the ethical standards of the responsible institutional committee and the revised 2000 Helsinki Declaration.

Medical charts from October 2016 to October 2019 from three Romanian tertiary centers, the Regional Institute of Gastroenterology and Hepatology Cluj-Napoca, the Floreasca Emergency Hospital Bucharest, and the Colentina Clinical Hospital, Bucharest, were retrospectively reviewed. Patients with symptomatic WON (abdominal pain, gastric/biliary obstruction or infected collections) at more than 4 weeks after the onset of acute pancreatitis were included in the analysis.

All patients underwent computed tomography (CT) evaluation before the drainage decision for assessing the size, the location, the content, the wall of WON and the presence of collateral circulation. Size of WON did not represent an inclusion criteria. Exclusion criteria were: platelets $<50000 /$ $\mathrm{mm}^{3}$ or international normalized ratio $>1.5$; suspicion of cystic neoplasm; multiloculated WON or WON extension into the lower abdomen; $>1 \mathrm{~cm}$ distance between WON and gut wall; and collateral circulation not avoidable during the procedure.

EUS drainage was done with the patient under general anesthesia and receiving broad-spectrum antibiotic prophylaxis. A therapeutic linear array echoendoscope, Olympus UCT 180, was used in combination with an Aloka F75 ultrasound device or EU-ME2 Premier Plus processor. Walled-off pancreatic necrosis were assessed for location, size, presence and amount of necrotic debris and collateral circulation. The size of WON was considered the largest diameter of the fluid collection. The presence of echogenic material in the WON cavity was suggestive of solid debris. As part of routine real-time EUS assessment, the amount of solid necrotic debris was measured by the endoscopist in $\mathrm{mm}$ (long axis and depth) and divided by the total size of the WON and the result represented the proportion of solid debris $(<30 \%, 30 \%-50 \%$, or $>50 \%)$. All four endosonographers (A.S., O.M., M.I., M.R.) experienced in EUS procedure ( over 3000 procedures each) quantified the proportion of solid debris (Figs. 1 and 2) based on intra-procedural measurements or by reviewing the real-time EUS movie.

The LAMS (15 mm diameter, AXIOS; Boston Scientific, Europe) was deployed as previously described [11]. The incoming fluid was suctioned to prevent lung aspiration. To avoid early obstruction of the LAMS by necrotic tissue, an additional plastic stent or nasocystic catheter (in case of pus inside WON, followed by $24 \mathrm{~h}$ continuous saline flushing) was placed through the LAMS, when considered necessary. A transpapillary stent was placed when imaging raised suspicion of a disconnected pancreatic duct.

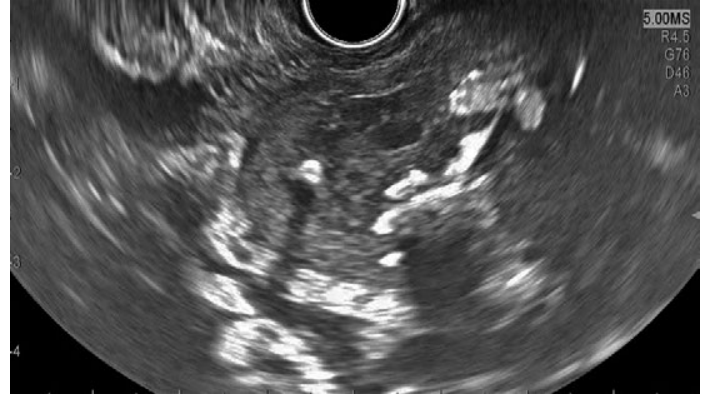

Fig. 1. Walled-off pancreatic necrosis visualized during endoscopic ultrasound with over $50 \%$ necrosis.

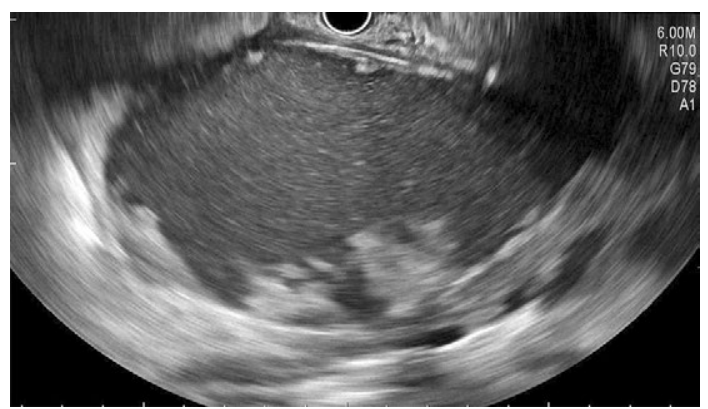

Fig. 2. Walled-off pancreatic necrosis visualized during endoscopic ultrasound with less than $30 \%$ necrosis.

Direct endoscopic necrosectomy was performed after the index procedure, "on-demand" if obstruction by necrotic tissue or inflammation (fever, leucocytosis, high C-reactive protein) occurred. Solid non-adherent necrotic debris was removed using rat-tooth forceps, small snare, or Dormia basket (Fig. 3 and 4) through a gastroscope inserted into the WON, followed by lavage with saline and half-strength hydrogen peroxide at endoscopist discretion (minor bleeding in the WON cavity).

Clinical success was defined as symptom resolution and WON resolution $(<3 \mathrm{~cm}$ diameter), without mortality or adverse events requiring surgery, without the recurrence of fluid collection or symptoms during follow-up [12]. Need for surgery was defined as surgical intervention (minimally invasive or open) for management of unresolved WON or related complications (multisystem organ failure [MSOF], stent dislodgement with symptomatic pneumoperitoneum,

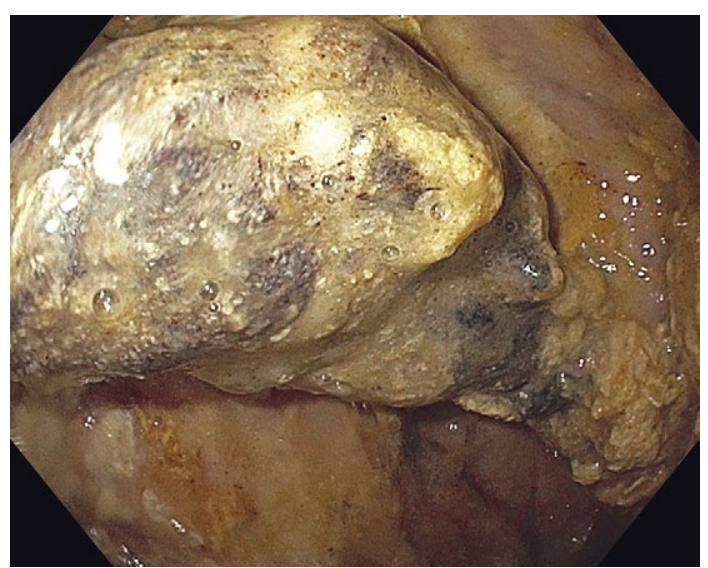

Fig. 3. Endoscopic view of necrosis inside the walled-off pancreatic necrosis during necrosectomy. 


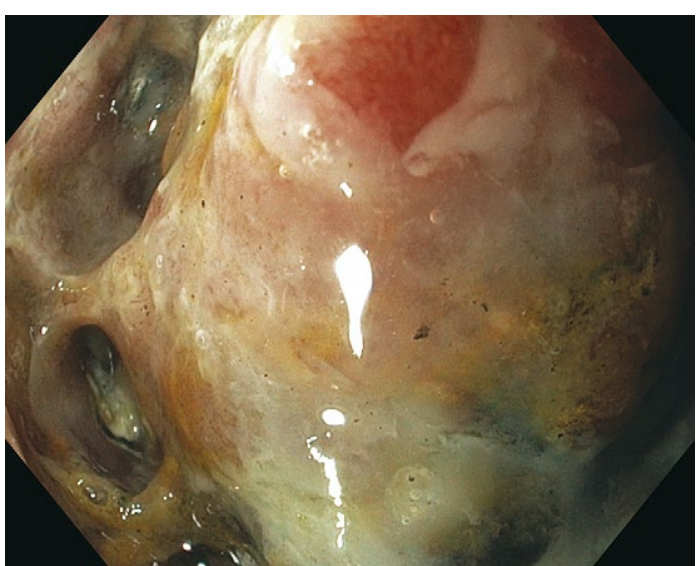

Fig. 4. Endoscopic aspect of the walled-off pancreatic necrosis after partial cleaning of walled-off pancreatic necrosis cavity. Some debris are still visible on the pink granular tissue.

untreatable infection, or intraabdominal bleeding). Recurrence was defined as recurrent symptomatic WON with a diameter more than $3 \mathrm{~cm}$ [12].

Patients were discharged after clinical resolution (without pain, jaundice, emesis, fever), normal leucocytes and CRP; they were readmitted if fever or abdominal pain developed. The management of complications was multidisciplinary.

Lumen-apposing metal stents were removed when CT showed a remnant cavity less than $3 \mathrm{~cm}$ without solid content. This was usually about 30 days from the index procedure but earlier if collateral circulation was present or later if the nutritional status was low. The patients without at least 6 months of follow-up after LAMS removal were considered as lost from follow-up and were not considered for long-term analysis.

Clinical examination and transabdominal ultrasound were done every 4-6 months afterwards, and a control CT scan was performed in the first year of follow-up for assessing recurrence.

Qualitative data were reported as number and percentage and quantitative as mean ( \pm standard deviation) or median (interquartile range $[\mathrm{IQR}]$ ). The Mann-Whitney test was used for quantitative data differences and the Fisher's Exact for group differences (chi-square test assumptions not being met). Spearman's rho was used to test for association between number of DEN procedures and estimated necrosis, and also WON size. Logistic regression was used to investigate independent predictors of successful drainage. Adjustments were made for gender and age as potential confounders. Tests were two-tailed and $\mathrm{p}<0.05$ was considered significant. The Statistica program (v.13; StatSoft, USA) was used.

\section{RESULTS}

While 51 patients were eligible for EUS drainage, 4 were excluded (collateral circulation, $\mathrm{n}=3$; WON $>1 \mathrm{~cm}$ from gastric wall, $n=1$ ), leaving 47. Men were younger than women (median [IQR] 52 years [47-61] vs. 65 [60-69]; $\mathrm{p}=0.003)$ and more frequently had pericollection collateral circulation $(71.88 \%$ vs. $40 \%, \mathrm{p}=0.036)$ (Table I).
Table I. Characteristics of patients and pancreatic fluid collections.

\begin{tabular}{|c|c|}
\hline tients & \\
\hline Age, mean \pm SD (range), years & $56.94 \pm 11.44(33-83)$ \\
\hline Men/Women, n (\%) & $32 / 15(68.08 / 31.92)$ \\
\hline $\begin{array}{l}\text { Etiology, n (\%) } \\
\text { Alcoholic } \\
\text { Biliary } \\
\text { Hypertriglyceridemia }\end{array}$ & $\begin{array}{l}27(57.45) \\
15(31.91) \\
1(2.13)\end{array}$ \\
\hline $\begin{array}{l}\text { Episodes of acute pancreatitis, } n(\%) \\
\text { One } \\
\text { Recurrent }\end{array}$ & $\begin{array}{l}44(93.62) \\
3(6.38)\end{array}$ \\
\hline $\begin{array}{l}\text { Indication for drainage, } \mathrm{n}(\%) \\
\text { Gastric obstruction and pain } \\
\text { Infection } \\
\text { Biliary compression }\end{array}$ & $\begin{array}{l}29(61.7) \\
17(36.17) \\
1(2.13)\end{array}$ \\
\hline $\begin{array}{l}\text { Previous drainage attempts, n (\%) } \\
\text { Surgical } \\
\text { ERCP } \\
\text { Percutaneous ultrasound-guided }\end{array}$ & $\begin{array}{l}3(6.38) \\
1(2.12) \\
1(2.12)\end{array}$ \\
\hline Walled-off pancreatic necrosis & \\
\hline $\begin{array}{l}\text { Location, } \mathrm{n}(\%) \\
\text { Head } \\
\text { Body/Tail } \\
\text { Whole pancreas }\end{array}$ & $\begin{array}{l}9(19.15) \\
29(61.70) \\
9(19.15)\end{array}$ \\
\hline $\begin{array}{l}\text { Dimensions, mean } \pm \mathrm{SD} \text { (range), } \mathrm{mm} \\
\text { Long axis } \\
\text { Depth }\end{array}$ & $\begin{array}{l}116 \pm 36(60 \text { to } 210) \\
83 \pm 25 \text { (50 to } 179)\end{array}$ \\
\hline $\begin{array}{l}\text { Collateral circulation, n (\%) } \\
\text { Yes } \\
\text { No }\end{array}$ & $\begin{array}{l}29(61.70) \\
15(38.30)\end{array}$ \\
\hline $\begin{array}{l}\text { Percentages of solid necrotic conten } \\
\quad<30 \% \\
30-50 \% \\
>50 \% \\
\end{array}$ & $\begin{array}{l}16(34.04) \\
16(34.04) \\
15(31.91)\end{array}$ \\
\hline
\end{tabular}

ERCP: endoscopic retrograde cholangiopancreatography; SD: standard deviation.

Technical success was noted in 46 of 47 patients (97.87\%) (Table II). In the remaining patient a highly fibrotic wall impeded LAMS passage. Therefore two plastic stents were placed instead, which provided a successful outcome. This patient, with less than $30 \%$ solid necrosis, was excluded from analysis.

A large proportion ( $>50 \%$ ) of solid necrotic tissue and DEN requirement were significantly associated: $\rho=0.45, p=0.0019$. No association was found between WON size and number of DENs $(\mathrm{p}=0.57)$.

No immediate complications occurred after LAMS placement.

Severe complications considered failure of EUS drainage occurred in six patients (13.04\%). Of these, five underwent surgery, namely: two patients with gastroduodenal pseudoaneurysms (who both died before 30-day follow-up); two dislodgements during necrosectomy with symptomatic pneumoperitoneum (operated with good outcomes); and one with unresponsive MSOF (who died 2 months later) (Table II). The sixth patient, had remnant WON after spontaneous dislodgement with elimination of LAMS, and underwent plastic stent drainage with a good outcome.

Lumen-apposing metal stents remained in situ for a median IQR: 21-42 days, range 2-104). Clinical success after LAMS removal was $40 / 46(87 \%)$. 
Table II. Drainage procedure characteristics and outcome

\begin{tabular}{|c|c|}
\hline \multicolumn{2}{|l|}{ Procedure characteristics } \\
\hline Technical success, $\mathrm{n}(\%)$ & $46 / 47(97)$ \\
\hline Transgastric approach, n (\%) & $46(100)$ \\
\hline \multicolumn{2}{|l|}{ Direct endoscopic necrosectomies (DENs) } \\
\hline \multicolumn{2}{|l|}{ Patients and procedures, $\mathrm{n}(\%)$} \\
\hline Total & $39(84.78)$ \\
\hline 1 & $13(33.33)$ \\
\hline 2 & $13(33.33)$ \\
\hline$\geq 3$ & $13(33.33)$ \\
\hline Median, IQR (range) & $2,1-3,(0-6)$ \\
\hline Additional plastic stent, n (\%) & $9(19.56)$ \\
\hline Additional nasocytic drain, n (\%) & $5(10.86)$ \\
\hline Additional transpapillary drainage, $\mathrm{n}(\%)$ & $2(4.34)$ \\
\hline $\begin{array}{l}\text { Duration of LAMS stenting, median (IQR) }\{\text { range }\} \text {, } \\
\text { days }\end{array}$ & $30(21-42)\{2-104\}$ \\
\hline \multicolumn{2}{|l|}{ Outcome } \\
\hline Immediate complications, $\mathrm{n}(\%)$ & $0(0)$ \\
\hline \multicolumn{2}{|l|}{ Complications $<30$ days } \\
\hline Gastroduodenal artery pseudoaneurysm, $\mathrm{n}(\%)^{*}$ & $2(4.34)$ \\
\hline $\begin{array}{l}\text { LAMS dislodgements during necrosectomy with } \\
\text { symptomatic pneumoperitoneum , } \mathrm{n}(\%)\end{array}$ & $2(4.34)$ \\
\hline $\begin{array}{l}\text { Spontaneous dislodgements with elimination of } \\
\text { LAMS , } \mathrm{n}(\%)\end{array}$ & $1(2.17)$ \\
\hline Infection, $\mathrm{n}(\%)^{\star *}$ & $9(19.56)$ \\
\hline Surgery & $5(10.86)$ \\
\hline \multicolumn{2}{|l|}{ Indications for surgery } \\
\hline Bleedings, n (\%) & $2(4.34)$ \\
\hline Pneumoperitoneum, n (\%) & $2(4.34)$ \\
\hline MSOF, n (\%) & $1(2.17)$ \\
\hline Mortality <30 days, $\mathrm{n}(\%)$ & $2(4.34)$ \\
\hline Mortality long-term, n (\%) & $3(6.51)$ \\
\hline Clinical success, $<30$ days, n (\%) & $40 / 46(86.96)$ \\
\hline Clinical success, long-term, n (\%) & $37 / 43(86.04)$ \\
\hline
\end{tabular}

IQR: interquartile range; LAMS: lumen-apposing metal stent; MSOF: multisystem organ failure. ${ }^{\star}$ Day 5 and 20 after LAMS placement. ${ }^{* *} 8$ patients responded to conservative therapy (antibiotics and direct endoscopic necrosectomy $[\mathrm{DEN}])$.

Mean follow-up was $13.37 \pm 9.88$ months (range 0-36). Three patients were lost to follow-up, thus 43 patients were analyzed. Clinical success was therefore obtained in $37 / 43$ patients (86.04\%). Recurrence of fluid collection less than 6 $\mathrm{cm}$ in diameter without necrosis after LAMSs removal was noted in six patients (13.9\%); five were asymptomatic and in one case, fluid extended into the lower abdomen producing pain which was drained percutaneously.

The large WON size was associated with unsuccessful drainage $(\mathrm{p}=0.032)$ (Suppl Table I), but when adjusted for age and gender, $\mathrm{OR}=1.022$, 95\%CI: 1.001-1.044; $\mathrm{p}=0.043$; Nagelkerke R2 $=0.369$.

In univariate analysis, number of DENs was significantly associated with $>50 \%$ solid necrosis $(\mathrm{p}=0.032)$, but not with WON size or location, or necrotic infection between DEN (Table III).

Hypoalbuminemia at index procedure was more frequently encountered in patients with infected necrosis during LAMS stenting $(4 / 9,44.44 \%)$ vs. those without $(4 / 37,10.81 \%)(p=0.036)$.

\section{DISCUSSION}

This multicenter retrospective study supports the hypothesis that DEN requirement after EUS-guided placement of a LAMS for WON drainage is associated with the proportion of solid necrotic material estimated preprocedurally. Also, the development of necrotic infection between DEN procedures could be related to the patient's nutritional status, as indicated by hypoalbuminemia, but did not affect DEN requirement.

The necrotic component negatively impacts the clinical success of plastic stent drainage of WONs compared to pseudocysts (63.2-72\% vs. 92-93.5\%) [13]. Computed tomography visualizes WON as fat globules, but their absence does not exclude necrosis. In detecting solid necrotic debris, CT is inferior to magnetic resonance imaging (MRI) $[14,15]$ and EUS (32\% vs. 92\%) [16]. Hence MRI is preferred to CT in WON management [6], EUS is comparable to MRI in diagnosing necrosis [17]. Walled-off pancreatic necrosis with more than $30 \%$ solid necrotic content were encountered in two-thirds of our patients, and in over half of 85 patients with WONs more than $10 \mathrm{~cm}$ [18]. Solid content more than $50 \%$ was noted in $31 \%$ $(15 / 47)$ in our study, and in $43 \%$ of 102 WONs elsewhere [12].

Table III. Demographic and clinical factors associated with the number of necrosectomies and acquisition of infection after lumen-apposing metal stent (LAMS) placement

\begin{tabular}{|c|c|c|c|c|c|c|}
\hline \multirow[t]{2}{*}{ Parameters } & \multicolumn{2}{|c|}{ No. of necrosectomies } & \multirow[t]{2}{*}{$\mathrm{p}$} & \multicolumn{2}{|c|}{ Infection of necrosis } & \multirow[t]{2}{*}{$\mathrm{p}$} \\
\hline & $\begin{array}{c}1-2 \\
(n=33)\end{array}$ & $\begin{array}{c}3 \text { or more } \\
(n=13)\end{array}$ & & $\begin{array}{c}\text { Yes } \\
(n=9)\end{array}$ & $\begin{array}{c}\text { No } \\
(n=37)\end{array}$ & \\
\hline \multicolumn{7}{|l|}{ Gender, $\mathrm{n}(\%)^{\mathrm{a}}$} \\
\hline Male & $23(69.70)$ & $8(61.54)$ & 0.72 & $7(77.78)$ & $24(64.86)$ & 0.40 \\
\hline Female & $10(30.30)$ & $5(38.46)$ & & $2(22.22)$ & $13(35.140$ & \\
\hline Age, years ${ }^{\mathrm{b}}$ & $59(50-68)$ & $53(49-61)$ & 0.17 & $56(47-61)$ & $58(50-67)$ & 0.44 \\
\hline \multicolumn{7}{|l|}{ Location, $\mathrm{n}(\%)^{\mathrm{a}}$} \\
\hline Head & $5(15.15)$ & $4(30.77)$ & 0.25 & $2(22.22)$ & $7(18.92)$ & $>0.99$ \\
\hline Body/tail & $28(84.85)$ & $9(69.23)$ & & $7(77.78)$ & $30(81.08)$ & \\
\hline Size, median (IQR), $\mathrm{mm}^{\mathrm{b}}$ & $108(93-140)$ & $108(82-130)$ & 0.66 & $120(90-140)$ & $108(93-130)$ & 0.59 \\
\hline \multicolumn{7}{|c|}{ Percentage of necrosis, $\mathrm{n}(\%)^{\mathrm{a}}$} \\
\hline$<30 \%$ & $12(36.36)$ & $3(23.08)$ & & $4(44.44)$ & $11(29.73)$ & 0.26 \\
\hline $30 \%-50 \%$ & $14(42.42)$ & $2(15.38)$ & & $1(11.11)$ & $15(40.54)$ & \\
\hline$>50 \%$ & $7(21.21)$ & $8(61.54)$ & 0.032 & $4(44.44)$ & $11(29.73)$ & \\
\hline
\end{tabular}

a: Fisher exact test; b: Mannn-Whitney test 
We performed DEN in $39 / 46$ patients (84\%), with $1-2$ procedures for $26 / 31$ patients with less than $50 \%$ solid necrosis, and 3 or more for $8 / 15$ patients with more than $50 \%$ solid necrosis (Table III), the DEN requirement being significantly associated with the percentage of solid content. Recognition is needed because a higher proportion of solid necrosis will entail more endoscopist effort, more intravenous sedations, risks in elderly patients with co-morbidities, higher costs and prolonged hospitalizations. Another retrospective study found that in 85 patients with WON (61 drained with plastic stents and 21 with metallic stents) those with more than $30 \%$ solid necrosis had significantly more DENs compared to those without (43.5\% vs.17.9\%) [18]. A retrospective analysis of 43 patients (plastic stent drainage), reported that more than $40 \%$ of solid debris dictated more aggressive treatment [19]. Kumta et al. found that a higher proportion of solid debris increased the need for DEN and the adverse events rate [20].

Walled-off pancreatic necrosis drainage with LAMS, with a large diameter [21] and enabling of DEN, is preferred over plastic stenting $[22,23]$. Our $86 \%$ clinical success with LAMS is comparable to the reported rates of $80-97 \%[12,22-24]$. They were better with interventional radiology support for pseudoaneurysm bleedings, although our rate of $4.34 \%(2 / 46)$ was below the reported range (5.1-15\%) [12, 25-27]. The higher need for surgery $(10.8 \%)$, compared to other studies [22, 23], was related to bleeding and loss of LAMS apposition during DEN, although we performed DEN only when necessary (obstruction/infection), avoiding immediate DEN during the index procedure. An ongoing prospective randomized study is investigating immediate DEN [28], as a retrospective study supported this approach [29].

This retrospective study has several limitations. First, there was no common drainage protocol relating to the timing for DEN or additional stenting, which could affect patient outcomes. Second, visual estimation of necrosis during EUS was operator-dependent. Third, the application of DEN depends on endoscopist experience and on local protocols that vary regarding optimal initiation [30], and procedure intervals $[31,32]$. Also, lack of facilities such as interventional angiography worsens patient outcomes.

\section{CONCLUSIONS}

The use of LAMS in WONs allows complete drainage and necrosectomy with good clinical success. Higher proportions of solid necrotic content dictate more DEN procedures. Necrotic infection during LAMS stenting is higher in patients with hypoalbuminemia, but is not associated with greater DEN requirement. Further prospective studies are necessary to support our findings.

Conflicts of interest: None to declare.

Authors contribution: A.S. conceived and drafted the study. A.S., S.B., M.I., M.R., G.C. and R.S wrote the manuscript. A.S., O.M., C.P., M.I., V.S, G.C. and M.R. selected the data. A.S., C.P., O.M., M.I., G.C., M.R., M.G., L.L., A.B., N.A.H., and R.S. managed the patients. S.B. performed the statistical analysis. All the authors reviewed and approved the final form of the paper.
Supplementary material: To access the supplementary material visit the online version of the J Gastrointestin Liver Dis at http://dx.doi. org $/ 10.15403 /$ jgld-3128

\section{REFERENCES}

1. van Santvoort HC, Bakker OJ, Bollen TL, et al. A conservative and minimally invasive approach to necrotizing pancreatitis improves outcome. Gastroenterology 2011;141:1254-1263. doi:10.1053/j. gastro.2011.06.073

2. van Brunschot S, van Grinsven J, van Santvoort HC, et al. Endoscopic or surgical step-up approach for infected necrotising pancreatitis: a multicentre randomised trial. Lancet 2018;391:51-58. doi:10.1016/ S0140-6736(17)32404-2

3. Alali A, Mosko J, May G, Teshima C. Endoscopic ultrasound-guided management of pancreatic fluid collections: update and review of the literature. Clin Endosc 2017;50:117-125. doi:10.5946/ce.2017.045

4. Sarathi Patra P, Das K, Bhattacharyya A, et al. Natural resolution or intervention for fluid collections in acute severe pancreatitis. Br J Surg 2014;101:1721-1728. doi:10.1002/bjs.9666

5. Manrai M, Kochhar R, Gupta V, et al. Outcome of acute pancreatic and peripancreatic collections occurring in patients with acute pancreatitis. Ann Surg 2018;267:357-363. doi:10.1097/ SLA.0000000000002065

6. Arvanitakis M, Dumonceau JM, Albert J, et al. Endoscopic management of acute necrotizing pancreatitis: European Society of Gastrointestinal Endoscopy (ESGE) evidence-based multidisciplinary guidelines. Endoscopy 2018;50:524-546. doi:10.1055/a-0588-5365

7. Baron TH, DiMaio CJ, Wang AY, Morgan KA. American Gastroenterological Association clinical practice update: management of pancreatic necrosis. Gastroenterology 2020;158:67-75.e1. doi:10.1053/j.gastro.2019.07.064

8. Expert Panel on Gastrointestinal Imaging; Porter KK, Zaheer A, et al. ACR Appropriateness Criteria Acute Pancreatitis. J Am Coll Radiol 2019;16:S316-S330. doi:10.1016/j.jacr.2019.05.017

9. Dhaka N, Samanta J, Kochhar S, et al. Pancreatic fluid collections: what is the ideal imaging technique? World J Gastroenterol 2015;21:1340313410. doi:10.3748/wjg.v21.i48.13403

10. Yoon SB, Lee IS, Choi MG. Metal versus plastic stents for drainage of pancreatic fluid collection: A meta-analysis. United European Gastroenterol J 2017;5:729-738. doi:10.1177/2050640618761702

11. Bang JY, ArnolettiJP, Holt BA, et al. An endoscopic transluminal approach, compared with minimally invasive surgery, reduces complications and costs for patients with necrotizing pancreatitis. Gastroenterology 2019;156:1027-1040.e3. doi:10.1053/j.gastro.2018.11.031

12. Chen YI, Yang J, Friedland S, et al. Lumen apposing metal stents are superior to plastic stents in pancreatic walled-off necrosis: a large international multicenter study. Endosc Int Open 2019;7:E347-E354. doi:10.1055/a-0828-7630

13. Varadarajulu S, Bang JY, Phadnis MA, Christein JD, Wilcox CM. Endoscopic transmural drainage of peripancreatic fluid collections: outcomes and predictors of treatment success in 211 consecutive patients. J Gastrointest Surg 2011;15:2080-2088. doi:10.1007/s11605011-1621-8

14. Morgan DE, Baron TH, Smith JK, Robbin ML, Kenney PJ. Pancreatic fluid collections prior to intervention: evaluation with MR imaging compared with CT and US. Radiology 1997;203:773-778. doi:10.1148/ radiology.203.3.9169703 
15. Kamal A, Singh VK, Akshintala VS, et al. CT and MRI assessment of symptomatic organized pancreatic fluid collections and pancreatic duct disruption: an interreader variability study using the revised Atlanta classification 2012. Abdom Imaging 2015;40:1608-1616. doi:10.1007/ s00261-014-0303-X

16. Medarapalem JB, Appasani S, Gulati A, et al. Characterization of fluid collections using quantification of solid debris in acute pancreatitis - a comparative study of EUS vs. CT for prediction of intervention. Gastrointest Endosc 2014;79(5 Suppl):AB445. doi:10.1016/j. gie.2014.02.637

17. Rana SS, Chaudhary V, Sharma R, Sharma V, Chhabra P, Bhasin DK. Comparison of abdominal ultrasound, endoscopic ultrasound and magnetic resonance imaging in detection of necrotic debris in walled-off pancreatic necrosis. Gastroenterol Rep (Oxf) 2016;4:50-53. doi:10.1093/ gastro/gou088

18. Guo J, Duan B, Sun S, et al. Multivariate analysis of the factors affecting the prognosis of walled-off pancreatic necrosis after endoscopic ultrasound-guided drainage. Surg Endosc 2020;34:1177-1185. doi:10.1007/s00464-019-06870-3

19. Rana SS, Bhasin DK, Sharma RK, Kathiresan J, Gupta R. Do the morphological features of walled off pancreatic necrosis on endoscopic ultrasound determine the outcome of endoscopic transmural drainage? Endosc Ultrasound 2014;3:118-122. doi:10.4103/2303-9027.131039

20. Kumta NA, Tyberg A, Bhagat VH, et al. EUS-guided drainage of pancreatic fluid collections using lumen apposing metal stents: An international, multicenter experience. Dig Liver Dis 2019;51:1557-1561. doi:10.1016/j.dld.2019.05.033

21. Teoh AY, Ng EK, Chan SM, et al. Ex vivo comparison of the lumenapposing properties of EUS-specific stents (with video). Gastrointest Endosc 2016;84:62-68. doi:10.1016/j.gie.2015.11.041

22. Hammad T, Khan MA, Alastal Y, et al. Efficacy and safety of lumenapposing metal sstents in management of pancreatic fluid collections: Are they better than plastic stents? A systematic review and metaanalysis. Dig Dis Sci 2018;63:289-301. doi:10.1007/s10620-017-4851-0

23. Siddiqui AA, Adler DG, Nieto J, et al. EUS-guided drainage of peripancreatic fluid collections and necrosis by using a novel lumen-apposing stent: a large retrospective, multicenter U.S. experience (with videos). Gastrointest Endosc 2016;83:699-707. doi:10.1016/j.gie.2015.10.020
24. Sharaiha RZ, Tyberg A, Khashab MA, et al. Endoscopic therapy with lumen-apposing metal stents is safe and effective for patients with pancreatic walled-off necrosis. Clin Gastroenterol Hepatol 2016;14:1797-1803. doi:10.1016/j.cgh.2016.05.011

25. Garcia-Alonso FJ, Sanchez-Ocana R, Peñas-Herrero I, et al. Cumulative risks of stent migration and gastrointestinal bleeding in patients with lumen-apposing metal stents. Endoscopy 2018;50:386-395. doi:10.1055/a-0581-9040

26. Brimhall B, Han S, Tatman PD, et al. Increased incidence of pseudoaneurysm bleeding with lumen-apposing metal stents compared to double-pigtail plastic stents in patients with peripancreatic fluid collections. Clin Gastroenterol Hepatol 2018;16:1521-1528. doi:10.1016/j.cgh.2018.02.021

27. Teoh AYB, Bapaye A, Lakhtakia S, et al. Prospective multicenter international study on the outcomes of a newly developed selfapproximating lumen-apposing metallic stent for drainage of pancreatic fluid collections and endoscopic necrosectomy. Dig Endosc 2020;32:391-398. doi:10.1111/den.13494

28. van Grinsven J, van Dijk SM, Dijkgraaf MG, et al. Postponed or immediate drainage of infected necrotizing pancreatitis (POINTER trial): study protocol for a randomized controlled trial. Trials 2019;20:239. doi:10.1186/s13063-019-3315-6

29. Yan L, Dargan A, Nieto J, et al. Direct endoscopic necrosectomy at the time of transmural stent placement results in earlier resolution of complex walled-off pancreatic necrosis: Results from a large multicenter United States trial. Endosc Ultrasound 2019;8:172-179. doi:10.4103/ eus.eus_108_17

30. Guo J, Saftoiu A, Vilmann P, et al. A multi-institutional consensus on how to perform endoscopic ultrasound-guided peri-pancreatic fluid collection drainage and endoscopic necrosectomy. Endosc Ultrasound 2017;6:285-291.doi:10.4103/eus.eus_85_17

31. Gornals JB, Consiglieri CF, Busquets J, et al. Endoscopic necrosectomy of walled-off pancreatic necrosis using a lumen-apposing metal stent and irrigation technique. Surg Endosc 2016;30:2592-2602. doi:10.1007/ s00464-015-4505-2

32. Tarantino I, Ligresti D, Tuzzolino F, et al. Clinical impact of EUS treatment of walled-off pancreatic necrosis with dedicated devices. Endosc Int Open 2017;5:E784-E791. doi:10.1055/s-0043-112494 